\title{
Familiarity impairments after anterior temporal-lobe resection with hippocampal sparing: Lessons learned from case NB
}

Stefan Köhler ${ }^{\mathrm{a}, \mathrm{b}}$, Chris B. Martin ${ }^{\mathrm{a}, \mathrm{c}}$

a The Brain and Mind Institute and Department of Psychology, University of Western Ontario, London, Ontario, Canada

${ }^{\mathrm{b}}$ Rotman Research Institute, Baycrest Centre, Toronto, Ontario, Canada

${ }^{\mathrm{c}}$ Department of Psychology, University of Toronto, Toronto, Ontario, Canada

Corresponding author: Dr. Stefan Köhler

The Brain and Mind Institute

Western Interdisciplinary Research Building

University of Western Ontario

London, ON, N6A 5B7, Canada

Tel.: +1 5196612111 ext. 86364

E-mail address: stefank@uwo.ca 


\begin{abstract}
We review evidence from an extensive single case study in an individual (NB) who underwent a rare left-sided anterior temporal-lobe resection with sparing of the hippocampus. Our study aimed to determine whether memory functions of perirhinal cortex, which was largely removed in the resection, can be impaired against a background of preserved hippocampus-dependent memory processing. This research was guided by the proposal that item-based familiarity assessment relies on contributions of perirhinal cortex, and that the hippocampus plays a unique role in the relational binding of items to episodic contexts, which is critical for recollection. Seven sets of findings have emerged from this research in NB and from follow-up work in other patients: (i) Familiarity impairments can be selective and be revealed with multiple methods; (ii) selective familiarity and selective recollection impairments can be double dissociated; (iii) selective familiarity impairments show material specificity; (iv) selective familiarity impairments extend to assessment of cumulative lifetime experience; (v) selective familiarity impairments are sensitive to degree of feature overlap between object concepts; (vi) selective familiarity impairments are associated with preserved task-related fMRI signals in the hippocampus; (vii) selective familiarity impairments can be observed in other lesion cases. Despite our main focus on the dual-process framework, we also discuss implications for the functional organization of the medial temporal lobes in broader terms. We argue that our findings shed light on this organization even if the functional specialization of different medial temporal structures is ultimately not fully captured with reference to the cognitive distinction between familiarity and recollection.
\end{abstract}

Keywords: recognition memory; recollection; concept; medial temporal lobe; temporal lobe epilepsy; perirhinal cortex; lesion 


\section{Introduction}

Fueled by the seminal report of severe anterograde amnesia in patient HM in the 1950s (Scoville and Milner, 1957), research in neurological patients with lesions to the medial temporal lobes (MTL) has played a crucial role in elucidating the functional organization of human memory, and in characterizing the contributions of its structures to memory and other cognitive functions. Even with the establishment of functional neuroimaging as a mainstay of cognitive neuroscience research, lesion studies in humans and other animals continue to advance our scientific understanding of memory. Dissociations between impaired and preserved aspects of behavioural performance play an important role in validating conceptual distinctions in cognitive theory, and they can provide key insight as to the necessity of contributions from specific brain regions to specific behaviours, cognitive processes, or computations (Rosenbaum et al. 2014; Clark and Maguire, 2016; Vaidya et al. 2019). Such dissociations are particularly valuable when lesion extent is focal and precisely documented, as well as when experimental paradigms are available to test theoretically derived predictions with high behavioural specificity. Dissociations between performance on tasks of declarative versus procedural memory established by Milner and colleagues in patient HM, for example, were a key discovery in showing that not all types of learning depend on MTL functioning (for reviews, see Squire, 2009; Eichenbaum, 2013). Research in another extensively studied individual with dense anterograde amnesia, patient $\mathrm{KC}$, revealed dissociations that were of critical theoretical importance for refining Tulving's influential theoretical distinction between episodic and semantic memory (for reviews, see Tulving, 2002; Rosenbaum et al. 2005). 
Lesion studies in humans have also made important contributions to our understanding of the intrinsic functional organization of the MTL. Neuroanatomical evidence indicates that the MTL of human and non-human primates is not a homogeneous region but consists of several different structures that can be distinguished based on their cytoarchitectonic composition, patterns of connectivity, and evolutionary history (see Aggleton, 2012; Murray et al. 2017, for review). Important distinctions have been drawn between the hippocampus, consisting of cornu ammonis (CA1-4), the dentate gyrus, and (depending on definition) the subicular complex, versus surrounding structures in the parahippocampal gyrus; the latter include entorhinal, perirhinal, and parahippocampal cortex. There appears to be near consensus in the neuroscience literature that the functions of the hippocampus differ from those of perirhinal and parahippocampal cortex. How best to characterize the functional role of these different MTL structures, however, remains a matter of intense debate, and it continues to drive much current research in cognitive neuroscience (Graham et al. 2010; Wixted and Squire, 2011; Moscovitch et al. 2016; Eichenbaum, 2017; Reagh and Ranganath, 2018). Because naturally occurring lesions that are restricted to specific MTL structures most frequently target the hippocampus, the bulk of pertinent lesion research has addressed the functional consequences of selective hippocampal damage (see Clark and Maguire, 2016; Moscovitch et al. 2016; Bird, 2017; Verfaellie and Keane, 2017, for reviews). It is generally recognized, however, that important insight can also be gained from studying patients with other lesion profiles that affect or spare specific MTL structures (e.g., Bohbot et al. 1998).

In the current article, we review a body of research that we conducted in an individual (NB) who underwent a rare unilateral anterior temporal-lobe resection that spared the 
hippocampus. The surgical removal, which served as treatment for intractable temporal-lobe epilepsy, included left perirhinal and entorhinal cortex, in addition to the amygdala and anterolateral temporal cortex. Over the course of several years, we conducted an extensive single case study in NB, aiming to determine whether memory functions of perirhinal cortex can be impaired against a background of preserved hippocampally-dependent memory functioning. Our research in NB was guided by the influential proposal, common to several theories of MTL organization, that the hippocampus plays a unique and necessary role in the relational binding of items to episodic contexts, and that item-based memory itself does not require hippocampal contributions (Aggleton and Brown, 1999; Davachi, 2006; Eichenbaum et al. 2007; Mayes et al. 2007). This proposal has been particularly influential in research on recognition memory, where it has been linked to cognitive dual-process models that distinguish between the assessment of item familiarity and recognition based on episodic recollection, i.e. the recovery of context in which an item was previously encountered (see Yonelinas, 2002, Diana et al. 2006, Wixted and Mickes, 2010 for review). While these two processes have been separated in the cognitive literature based on multiple dimensions, including their phenomenological expression as 'knowing' versus 'remembering' (Tulving, 1985), their differential reliance on item versus context information has been most central to queries in cognitive neuroscience (see Aly and Ranganath, 2018; Stark et al. 2018, for discussion).

We summarize the outcome of our studies as seven sets of findings that we have synthesized from five primary research papers on NB (Bowles et al. 2007; Bowles et al. 2010; Bowles et al. 2011; Martin et al. 2011; Bowles et al. 2016; see Table 1), and from closely related work in other patients that followed up on this case study (Martin et al. 2012, 2019; Brandt et 
al. 2016, 2018; Schoemaker et al. 2016, 2017). While our main theoretical emphasis in interpretation will be placed on the dual-process framework that guided our research, we will also discuss implications of these findings for the functional organization of the MTL in broader terms. We will argue that our findings shed light on this organization even if the division of labour between different MTL structures can ultimately not be fully captured by dual-process models of recognition memory.

\section{Case Description}

NB is a female right-handed university-educated individual who was 21 years old at the start of our investigation. A neuropsychologist involved in clinical evaluation of individuals with epilepsy referred her to us for experimental investigation of memory abilities, based on the rare surgical resection with hippocampal sparing that NB had undergone. We began this research project 9 months post surgery, and we conducted our experiments over a period of approximately 5 years. As described in our first paper that resulted from this investigation (Bowles et al. 2007), NB developed temporal-lobe epilepsy at age 11. Epilepsy initially manifested with simple partial seizures. Subsequently, she experienced multiple generalized tonic-clonic seizures and frequent stereotyped complex partial seizures that proved resistant to medication. Her seizures were often accompanied by déjà vu experiences as part of an aura. An MRI scan obtained in the context of a detailed clinical examination prior to surgical intervention revealed a mass in the left amygdala, which was most consistent with classification as a ganglioglioma. Given that this mass did not infiltrate the hippocampus, NB underwent a rare unilateral lesionectomy that targeted the most anterior extent (approximately $1.7 \mathrm{~cm}$ ) of 
the left lateral and medial temporal lobe, while aiming to spare the hippocampus. This surgery provided full relief from seizures. As a consequence, NB no longer experienced déjà vu as part of any aura following surgery (we note, however, that we did not query about other types of déjà vu nor about other unusual metacognitive memory experiences).

A high-resolution structural MRI scan confirmed that, in addition to the majority of tissue in the amgydala, temporo-polar and antero-lateral cortex, the resection encroached on entorhinal and perirhinal cortex, but spared the hippocampus and parahippocampal cortex. An MRI-based 3D reconstruction of NB's medial temporal lobe is depicted in Figure 1A (see Bowles et al. 2007, Fig. 1, Supplementary Fig. 2, and Supplementary Table 2 for further documentation). MR volumetry revealed volume reductions in left (as compared to right) perirhinal and entorhinal cortex of $43 \%$ and $58 \%$, respectively. While there was also a $17 \%$ reduction of volume in the left as compared to right hippocampus, this abnormality was visible on NB's clinical pre-operative MRI as well. It appeared to reflect mild atrophy that was confined to regions posterior to the most posterior extent of the surgical resection, contrasting with the abrupt volume loss in perirhinal and entorhinal cortices where the surgery occurred.

When examined with clinical neuropsychological testing several weeks post-surgery, NB displayed normal cognitive functioning in all domains probed, including declarative memory, with the only noteworthy feature being a low average score (21 percentile) on a test of semantic fluency (see Bowles et al. 2007, Supplementary Table 2). The observation of intact post-surgical memory functioning also matched NB's own subjective impression. From her perspective, the surgery did not have any cognitive side effects, and her participation in all our research was characterized by a high motivation to demonstrate normal functioning. Of critical 
relevance for the impairments we observed on our experimental memory tasks described below, there was also no reference to abnormal (or absent) feelings of familiarity in her anecdotal reports of post-surgical cognitive status. When we explicitly inquired about familiarity, the only potential abnormality that came to her mind was a subjective sense of delays in tuning into topics of conversation with friends or family when they concerned shared past experiences. It is not straightforward to interpret this subjective impression, but it is possible that the perceived delay reflects an initial lack of familiarity or perceived fluency with verbally apprehended conversation topics.

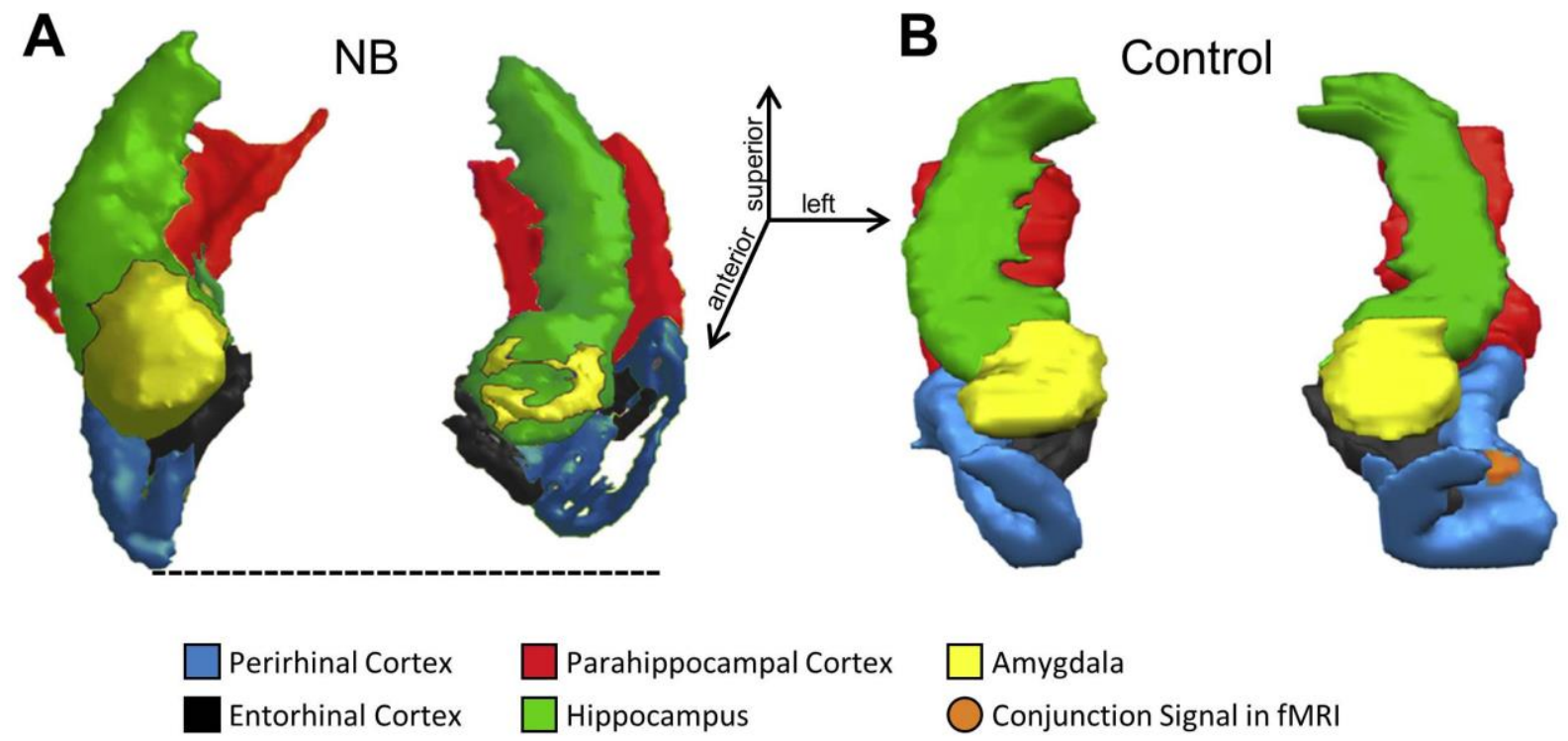

Figure 1. MRI based 3D anatomical reconstruction of $(A)$ patient NB's medial temporal lobe structures after left-sided surgical resection, and (B) those of a representative participant in an fMRI study that revealed perirhinal cortex activation for two memory tasks on which NB showed impairments. The left-sided perirhinal cortex region displayed in (B) tracked behavioral ratings for frequency judgments of recent item exposure as well as for judgments of cumulative lifetime familiarity in healthy participants. Note the close correspondence between this activation cluster and the anterior part of left perirhinal cortex that was resected in patient NB. For further methodological details see Duke et al. (2017) and Bowles et al. (2007). Reprinted from Cortex, 89, Duke et al. Perirhinal cortex tracks degree of recent as well as cumulative lifetime experience with object concepts, 61-70, 2017, with permission from Elsevier. 


\section{Findings}

\subsection{Familiarity impairments can be selective and be revealed with multiple methods}

Given that NB's lesion includes perirhinal cortex but spares the hippocampus, the primary goal of our research was to examine whether she might display impairments in itembased familiarity assessment in combination with intact recollection of episodic context on experimental tasks of recognition memory (Bowles et al. 2007). We initially focused on memory for verbal materials because of the large body of evidence indicating that the most pronounced effects of left-sided temporal-lobe resections occur in this domain (for meta-analysis, see Lee et al., 2002).

There are multiple methods for probing the contributions of familiarity assessment and recollection to performance on recognition memory tasks. These methods can provide estimates of the accuracy of familiarity and recollection based on performance measures aggregated across multiple trials. Each of these methods relies on specific assumptions as to how the two processes are expressed in behaviour, and some of these assumptions remain controversial (e.g., Yonelinas, 2002; Wixted and Mickes, 2010). Therefore, we sought converging evidence from multiple methodological approaches in our efforts to reveal a familiarity-specific impairment in NB. In our selection of methods, we were careful to ensure that markers of recollection would not target memory for a specific contextual attribute, as examined, for example, in source-memory tasks (e.g., whether an item was previously presented on the left or right side of the screen), but that it captured recollection of contextual information more broadly. When recollection of only specific contextual information is probed, 
it is difficult to establish that the measure available to estimate contributions of familiarity is not contaminated by recollection of other contextual information (see Bastin and Besson, 2017, for further discussion).

In our initial two experiments, we employed the most widely used method for separating familiarity from recollection, i.e., the Remember/Know (RK) procedure. In our administration of this task, it was emphasized that Remember responses should be endorsed if any kind of episodic contextual information about the initial item encounter came to mind. RK judgments were obtained in a second step for items endorsed as old in initial recognition judgments. In calculating estimates of both processes from the pattern of RK responses, we assumed their independence (Yonelinas, 2002). This assumption implies that, on any given trial, the recollection of contextual detail may or may not be associated with successful familiarity assessment for the item (see Montaldi et al. 2006, for detailed discussion). In scoring the contributions of familiarity to task performance, we also assumed that familiarity assessment is a signal-detection process that operates on a memory-strength signal for the items (Yonelinas, 2002). Our results revealed impairments in NB's familiarity-based discrimination in both experiments; although above chance level, her scores fell below those of every individual control participant. By contrast, there was no evidence for impairments in her recollection scores nor in the measure of overall recognition discrimination. In fact, NB's recollection score was above that of all control participants in one of these experiments, and in the upper normal range in the other. That the observed familiarity impairments do not reflect difficulties in following task instructions is suggested by follow-up work, which revealed that NB's familiaritybased discrimination was normal when recognition memory was tested with the same RK 
procedure for non-verbal stimulus material (Martin et al. 2011; see section 3.3 below). Another observation we made is that NB's overall recognition performance on this task, expressed using the discriminability measure $d^{\prime}$, was clearly within the unimpaired range. The latter finding suggests that preserved recollection abilities dominate her recognition judgments of prior occurrence, which is supported by the observation that she provided the largest number of Remember responses in our study as well (Bowles et al., 2007, see Supplementary Materials Table 3).

We also estimated NB's familiarity and recollection abilities in a verbal recognitionmemory test that required confidence ratings, rather than classification of the retrieval experience as remembering or knowing, and that involved modeling of Receiver Operating Characteristics (ROCs; Bowles et al. 2007). In calculating process-specific estimates of performance, we relied on Yonelinas' dual-process model that, again, assumes familiarity assessment to be a signal-detection process, but that models recollection as a high-threshold process (Yonelinas, 2002). Analyses of these estimates provided additional evidence for a selective familiarity impairment in NB, with abnormalities being most notable when items had been encoded under semantic (i.e., deep) orienting instructions in the study phase. In line with the predominance of Remember responses in the RK paradigm, she also provided the largest number of high confidence responses in this experiment. Quantitative comparison of the shape of NB's ROC curve with that of control participants provided additional support for the conclusion of impaired familiarity.

Expressing confidence in old/new recognition memory decisions and making RK judgments rely on metamemory. To rule out the possibility that the impairments we observed 
in NB reflect a deficit in metamnemonic processing, we also conducted two experiments that did not require any reference to metamemory, and that could be argued to reflect a less subjective probing of familiarity assessment. One of them involved the use of simple old/new recognition-memory judgments in combination with experimental conditions that maximize reliance on item-based familiarity (Bowles et al. 2007). Here, we built on prior behavioural and electrophysiological research demonstrating that familiarity signals become available earlier than recollection (Hintzman and Curran, 1994; Yonelinas and Jacoby, 1994; Düzel et al. 1997; Curran, 2000; Basile and Hampton, 2013), including work with intracranial recordings that directly compared old-new item-memory signals in perirhinal cortex and the hippocampus (Staresina et al., 2012; Despouy et al., 2019). While we recognize that differences in response times for familiarity- versus recollection-based responses do not follow this pattern in all behavioural paradigms (e.g., Dewhurst et al., 2006), we employed a simple yes-no recognition memory task with varying response-deadlines that had provided clear evidence for a corresponding dissociation in prior research (Boldini et al., 2004). Accordingly, we reasoned that the accuracy of NB's recognition-memory judgments should be disproportionately affected by the presence of her lesion when such judgments have to be made rapidly. Indeed, when we examined the accuracy of NB's recognition judgments under two different response deadlines (2,000 vs. $400 \mathrm{~ms}$ ) in comparison to control participants, we found a pattern in direct support of our hypothesis. Specifically, we calculated performance as hits minus false alarms, and then expressed it as a ratio for the two response deadline conditions; NB was disproportionately affected by the requirement to make a faster response, as reflected in a lower ratio. 
A second approach we took in probing NB's sensitivity to graded differences in itemmemory strength, without any reference to metamemory, involved manipulation of the number of item exposures (repetitions) in the experimental study phase, and the administration of frequency judgments at test. Evidence from computational modeling and behavioural research on retrieval dynamics suggests that under many experimental conditions item-based familiarity signals are the primary source on which frequency judgments are based (Hintzman and Curran, 1994, but see Hintzman, 2004). In our experiment with NB, we minimized the likelihood of any contributions from recollection to frequency judgments by manipulating item exposure in small increments over a large range in a fast-paced lexical decision task, and by including no items without any prior study exposure (i.e., no novel lures) at test (Bowles et al. 2016). To obtain a sensitive measure of memory accuracy, we conducted regression analyses that related judged frequency to the objective frequency of presentations at study, using the slope as a marker of performance. Our analyses revealed a significantly reduced slope in NB as compared to control participants, providing additional support for the conclusion that her memory discrimination based on item-strength is impaired.

Although in several of the experiments described in this section the reduced accuracy of NB's memory judgments primarily reflected an increase in false alarm rates, a systematic examination with measures derived from signal detection theory revealed that these abnormalities cannot solely be attributed to a shift in criterion placement. Rather, these analyses consistently point to an impairment in familiarity-based memory discrimination (see Martin et al. 2011, for further detail and discussion). We note, however, that, although impaired, NB consistently performed above chance level in our estimates of familiarity-based 
discrimination, which is in line with anecdotal evidence that she does not lack feelings of familiarity in everyday behaviour.

\subsection{Selective familiarity and selective recollection impairments can be double dissociated}

A particularly powerful way to reveal independence for two cognitive processes at the level of brain mechanisms is to demonstrate a double dissociation of lesion effects (Teuber, 1955; Vaidya et al. 2019; but see Dunn et al. 2003). A critical question to ask, therefore, is whether selective damage to the hippocampus can lead to the opposite pattern of behavioural deficits as that observed in NB, namely an impairment in recollection combined with intact familiarity assessment. This question is of special importance in research on the functional organization of the MTL as it has been suggested that ostensibly unique contributions of different MTL structures revealed with neuroimaging methods may reflect differential sensitivity of these structures to overall memory strength, rather than computations in the service of distinct memory processes. While Rugg and colleagues have reviewed numerous aspects of the extant neuroimaging literature that is incompatible with this view (Rugg et al. 2012; see also Staresina et al. 2013, for compelling evidence from intracranial recordings), observing a double dissociation of lesion effects could provide additional compelling evidence to argue against such a strength-based account.

When we planned to conduct a study with the goal of establishing a double dissociation, there were several published reports of selective recollection impairments in association with restricted hippocampal lesions in humans (Vargha-Khadem et al. 1997; Mayes et al. 2002; Yonelinas, et al. 2002; Aggleton et al. 2005). There were other studies, however, that had 
revealed impairments in both processes in association with such lesions (Manns et al. 2003; Cipolotti et al. 2006; Gold et al. 2006; Wais et al. 2006). Differences in etiology across patients, and differences in tasks across studies are two (among several other) factors that have been suggested to account for this discrepancy in findings (Wixted and Squire, 2004; Yonelinas et al. 2004; Holdstock, et al. 2008; Turriziani, et al. 2008). Against this background, we aimed to match etiology and use identical tasks for the comparison between patients with hippocampal lesions and NB. We identified a group of 11 patients who, like NB, had undergone unilateral surgical treatment of intractable temporal-lobe epilepsy ( $n=6$ left-sided). Unlike in NB, the surgical approach pursued in these patients was a unilateral stereotaxic amygdalohippocampotomy that aimed to target the hippocampus and amygdala, while sparing surrounding temporal-lobe structures, including rhinal cortices (Parrent and Blume, 1999). We administered one of the RK tasks employed in our initial research on NB to these individuals as well as to a new group of matched control participants (Bowles et al. 2010).

As compared to control participants, patients who had undergone a unilateral stereotaxic amygdalohippocampotomy were found to have significantly reduced recollection scores but normal scores of familiarity-based discrimination. In patients with left- but not those with right-sided lesions these selective recollection impairments were associated with lower overall recognition-memory performance. Given that NB's familiarity impairments were not associated with reduced overall recognition-memory performance on the same task, we also identified an individual with a left-sided lesion in this group who obtained a recognition score comparable to that in NB; critically, this person still exhibited a selective impairment in recollection. In a direct comparison between this individual and NB, we revealed a double 
dissociation on z-scored (relative to healthy control participants) accuracy measures of recollection and familiarity at matched levels of overall recognition accuracy. This pattern indicates that selective recollection impairments do not necessarily reflect a stronger form of memory impairment than selective impairments in familiarity. For the interpretation of this double dissociation, we emphasized that the hippocampus was targeted by surgery in one case but spared in the other. Because the amygdala was targeted in both treatment approaches, our findings suggest that damage to the amygdala cannot account for the observed dissociation in behavioural performance.

\subsection{Selective familiarity impairments show material specificity}

While recent research on functional specialization in the MTL has primarily focused on the issue of whether the hippocampus, perirhinal cortex and parahippocampal cortex make distinct contributions to memory and cognition, an older neuropsychological literature addressed whether left- versus right-sided MTL structures differ in their functional role (for reviews, see Smith, 1989; Lee et al. 2002; Saling, 2009). A large body of evidence from patients with unilateral temporal lobe epilepsy has demonstrated primarily verbal memory deficit in association with left sided lesions, supporting the notion that hemispheric differences in MTL functioning are, at least in part, determined by the nature of the stimuli processed in memory (Milner, 1972; Lee et al. 2002). Curiously, there are also some findings from studies in patients with large unilateral temporal-lobe lesions suggesting that familiarity-based recognition might show more noticeable laterality effects than recollection (Cohn et al. 2009; Aly et al. 2010). 
Therefore, having established that NB displays impairments that are selective for familiarity assessment, we next asked whether these impairments might also show material-specificity.

For our investigation of material specificity, we administered three separate recognition-memory tests with different types of stimuli, but the same type of RK procedure used in our prior experiments with NB (Martin et al. 2011). Because differences in materials are often confounded with differences in corresponding semantic knowledge, we aimed to minimize semantic processing demands across all materials tested. For the verbal test, we selected auditorily presented non-words as stimuli, which heavily rely on phonological processing. For the non-verbal tests, we employed novel faces and abstract designs as stimuli, which heavily rely on visual discrimination between exemplars that are difficult to verbalize. Results from these experiments showed that NB exhibits a deficit in recognition memory for pronounceable non-words that reflects, in line with our previous findings, a specific impairment in familiarity assessment with preservation of recollection. Examination of her performance scores and process estimates for abstract pictures and faces, by contrast, did not reveal any abnormalities. Importantly, this dissociation across materials emerged even though task difficulty, as estimated based on recognition performance in control participants, was matched across non-words and faces. While these tasks also differed in terms of sensory modality in which stimuli were encountered, we note that in our prior work NB's impairments in familiarity assessment were observed regardless of whether words were presented visually or auditorily. Differences in sensory modality, therefore, do not seem to account for the dissociation observed in NB. Taken together, these findings indicate instead that NB's impairments in familiarity are material specific and include abnormal memory processing of phonological 
aspects of verbal material (in addition to conceptual aspects as discussed in Sections 3.4 and

3.5). In more general terms, they provide support for the idea that the neural mechanisms and representations that support familiarity assessment in the temporal lobe operate in a manner that is tied to the specific stimulus class being probed. Indeed, this conclusion is also supported by recent functional neuroimaging research from our laboratory and from other groups, which has highlighted differences in activation patterns in the MTL associated with the familiarity of different stimulus classes even within the same hemisphere (Martin et al. 2013; Kafkas et al. 2017; Martin et al. 2018a).

\subsection{Selective familiarity impairments extend to assessment of cumulative lifetime experience}

Familiarity is typically probed in humans with recognition-memory tasks for a list of items that were encountered in an initial experimentally controlled study phase. When meaningful stimuli such as words or pictures of common objects are used as items, participants must judge their familiarity in relation to the recent study phase rather than with respect to their lifetime of experience with the corresponding object, which may have involved hundreds or thousands of encounters in many different episodic contexts. From this perspective, most research with classic recognition-memory paradigms has probed recent incremental changes in familiarity rather than absolute or cumulative levels (Mandler, 1980). In psychological research on the structure of object concepts (i.e., the thing a word or picture makes reference to), investigators often obtain measures of the perceived cumulative lifetime familiarity of each item. These ratings show considerable consistency across participants in normative studies of 
concept knowledge. Moderate correlations of these ratings with objective word frequency point to some external validity as well (Cree and McRae, 2003; Schröder et al. 2012; MorenoMartinez et al. 2014). Judgments of cumulative lifetime familiarity and familiarity-based responses in recognition-memory tasks can be considered similar in that both involve assessment of prior item exposure without any requirement to recover pertinent episodic contextual information. Critically, there is also evidence from functional neuroimaging to suggest that perirhinal cortex tracks the outcome of both types of memory judgments (Figure 1B; Duke et al. 2017).

We conducted a series of experiments in NB that aimed to address whether the impairments we revealed when assessing familiarity for items encountered in a recent study list would extend to abnormalities in judging the cumulative familiarity with object concepts based on lifetime experience (Bowles et al. 2016). Using the type of judgments employed in the semantic-memory literature on object concepts with words as cues, we did indeed reveal abnormalities in her behaviour. Specifically, NB's ratings were significantly less correlated with the ratings of matched control participants than ratings of control participants with each other (note that objective accuracy cannot be scored). Because these reduced correlations remained present even when pictures were offered as additional cues, our findings suggest that they are tied to familiarity assessment at the level of object concepts. Consistent with the functional neuroimaging findings on perirhinal cortex previously mentioned (Figure 1B; Duke et al. 2017), our findings in NB therefore provide support for a functional link between the assessment of recent changes in familiarity, as probed with experimental study-test paradigms, and the assessment of cumulative lifetime experience accrued outside the laboratory. 
TABLE 1. Summary of behavioural findings in case NB

\begin{tabular}{|c|c|c|c|c|c|}
\hline Study & Material & Encoding Task & Retrieval Task & $\begin{array}{l}\text { Measure revealing } \\
\text { impairments in NB }\end{array}$ & $\begin{array}{l}\text { NB's z-score } \\
\text { relative to } \\
\text { controls }\end{array}$ \\
\hline \multicolumn{6}{|c|}{ Bowles et al., 2007 (Section 3.1) } \\
\hline Exp. 1 & Words & $\begin{array}{l}\text { Deep - } \\
\text { Pleasantness Rating }\end{array}$ & Remember/Know & $\begin{array}{l}\text { Familiarity } \\
\text { discrimination }\end{array}$ & -1.83 \\
\hline Exp. 2 & Words & $\begin{array}{l}\text { Deep - } \\
\text { Sentence } \\
\text { Verification }\end{array}$ & Remember/Know & $\begin{array}{l}\text { Familiarity } \\
\text { discrimination }\end{array}$ & -2.12 \\
\hline \multirow{2}{*}{ Exp. 3} & \multirow{2}{*}{ Words } & $\begin{array}{l}\text { Deep - } \\
\text { Abstract/Concrete }\end{array}$ & $\begin{array}{l}\text { Confidence in } \\
\text { Old/New Judgments } \\
\text { (ROC) }\end{array}$ & $\begin{array}{l}\text { Familiarity } \\
\text { discrimination }\end{array}$ & -1.98 \\
\hline & & $\begin{array}{l}\text { Shallow - } \\
\text { Syllabic Counting }\end{array}$ & $\begin{array}{l}\text { Confidence in } \\
\text { Old/New Judgments } \\
\text { (ROC) }\end{array}$ & $\begin{array}{l}\text { None (Familiarity } \\
\text { discrimination } \\
\text { borderline) }\end{array}$ & -1.05 \\
\hline Exp. 4 & Words & $\begin{array}{l}\text { Deep - } \\
\text { Abstract/Concrete }\end{array}$ & $\begin{array}{l}\text { Old/New Judgments } \\
\text { with Response } \\
\text { Deadline }\end{array}$ & $\begin{array}{l}\text { Ratio of recognition } \\
\text { discrimination short } \\
\text { vs long deadline }\end{array}$ & -2.05 \\
\hline \multicolumn{6}{|c|}{ Martin et al., 2011 (Section 3.3) } \\
\hline Exp. 1 & $\begin{array}{l}\text { Pronounceable } \\
\text { Non-Words }\end{array}$ & $\begin{array}{l}\text { Shallow - } \\
\text { Syllabic Counting }\end{array}$ & Remember/Know & $\begin{array}{l}\text { Familiarity } \\
\text { discrimination }\end{array}$ & -3.45 \\
\hline Exp. 2 & $\begin{array}{l}\text { Abstract } \\
\text { Pictures }\end{array}$ & $\begin{array}{l}\text { Shallow - } \\
\text { Field of View }\end{array}$ & Remember/Know & None & -0.05 \\
\hline Exp. 3 & Faces & $\begin{array}{l}\text { Deep - } \\
\text { Intelligence Rating }\end{array}$ & Remember/Know & None & -0.43 \\
\hline \multicolumn{6}{|c|}{ Bowles et al., 2016 (Section 3.4) } \\
\hline Exp. 1 & Words & $\begin{array}{l}\text { Deep - } \\
\text { Lexical Decision }\end{array}$ & $\begin{array}{l}\text { Frequency } \\
\text { Judgments }\end{array}$ & $\begin{array}{l}\text { Slope of judged vs } \\
\text { actual frequency }\end{array}$ & -2.02 \\
\hline Exp. 2 & Words & $\mathrm{N} / \mathrm{A}$ & Lifetime Familiarity & $\begin{array}{l}\text { Inter-subject } \\
\text { correlation }\end{array}$ & -1.91 \\
\hline Exp. 3 & $\begin{array}{l}\text { Words } \\
\text { and Pictures }\end{array}$ & $\mathrm{N} / \mathrm{A}$ & Lifetime Familiarity & $\begin{array}{l}\text { Inter-subject } \\
\text { correlation }\end{array}$ & -4.91 \\
\hline
\end{tabular}

\subsection{Selective familiarity impairments are sensitive to degree of feature overlap of object} concepts

The findings we obtained with judgments of cumulative lifetime familiarity in NB

(Bowles et al. 2016) and with fMRI in healthy individuals (Figure 1B; Duke et al. 2017) add to a growing body of evidence that implicates perirhinal cortex in object processing outside the 
context of classic recognition-memory tasks, and that links left perirhinal cortex to the conceptual processing of object concepts. At the theoretical level, this body of evidence has led to the suggestion that perirhinal cortex may reflect the apex of the processing hierarchy for objects in the ventral visual pathway (Murray and Bussey, 1999; Murray et al. 2007), and that the representations of objects carried at this level allow for fine-grained discrimination when objects are highly similar due to significant feature overlap (e.g., a horse and a donkey versus a horse and an elephant; see Duke et al., 2017; Martin et al., 2018b, for further discussion and illustrations). Studies conducted with fMRI in combination with sophisticated pattern analysis techniques have shown, for example, that activation patterns in left perirhinal cortex during various tasks, including object naming and feature verification, reflect degree of semantic feature overlap. Findings from a recent fMRI study with this type of methodological approach have also revealed that left perirhinal cortex allows for integrative coding of visual and abstract semantic object features when words are used as cues to access this information (Martin et al. 2018b).

Lesion-based research addressing the influence of feature overlap on memory judgments is currently limited (but see Kivisaari et al. 2013). Given the increasing influence of models of MTL organization that place emphasis on the nature of representations in characterizing functional contributions of different structures (Murray et al. 2007; Graham et al. 2010; Cowell et al. 2019), we aimed to determine whether concept similarity, as reflected in degree of semantic feature overlap, might also shape the abnormalities NB exhibits in making judgments of lifetime familiarity (Bowles et al. 2016). Here, we took advantage of the large sample of concepts ( $\mathrm{N}=541)$ for which we obtained her ratings, and separately examined them 
for the 100 concepts with the highest versus lowest normative scores of feature overlap. Analyses of inter-subject correlations for both item sets revealed in two separate experiments that NB's ratings were abnormal only when object concepts had a high degree of feature overlap with the other items in the set. This pattern of abnormalities clearly indicates sensitivity of her memory judgments to 'concept structure'. It also hints that NB might exhibit broader difficulties in making fine-grained distinctions between object concepts outside the realm of memory tasks. Given its theoretical importance, we will return to a more extensive discussion of this idea in the general section on theoretical implications of our findings in NB.

\subsection{Selective familiarity impairments are associated with preserved task-related fMRI signals in the hippocampus}

Aside from questions concerning the dual process model, a broader impetus for the research we conducted in NB was to determine whether memory functions of perirhinal cortex can be impaired against a background of preserved hippocampally-dependent memory functioning. To the extent that performance on the tasks that revealed preserved recollection in NB is indeed dependent on hippocampal integrity, which we directly demonstrated for one such task as part of the reported double dissociation (Bowles et al. 2010), the behavioural findings reviewed so far suggest an affirmative answer. At the same time, our behavioural findings do not directly address whether NB's hippocampus, specifically that in the left hemisphere, still shows signs of functional integrity after the surgical intervention. This issue gains in importance when one considers patterns of anatomical connectivity between MTL structures, and between the MTL and other cortical structures. Neuroanatomical evidence in 
human and non-human primates indicates that perirhinal and entorhinal cortex represent critical nodes in the convergent, reciprocal projections between neocortical association areas and the hippocampus (Lavenex and Amaral, 2000; Kahn et al. 2008; Aggleton et al. 2012; Libby et al. 2012). Damage to rhinal cortices will thus likely also lead to partial cortical deafferentiation of the hippocampus.

We conducted a functional neuroimaging study in which we directly examined the functional integrity of NB's left hippocampus using fMRI BOLD responses as a marker (Bowles et al. 2011). We focused on hippocampal novelty signals, given that such signals have been linked to processing of the kind of relationships that are critical for episodic recollection, and given that they can be reliably measured in individual participants with a block design (e.g., Köhler et al. 2005; Kumaran and Maguire, 2006; Poppenk et al. 2008). Specifically, we compared fMRI responses to novel versus repeated sentences, each of which described a unique episode (e.g., 'As he strolled along the deserted beach, the stranded sailor was overjoyed to see the cruise ship on the horizon'). These comparisons revealed robust novelty responses in NB's left and right hippocampus. In the surgically treated left hemisphere, her hippocampal responses closely resembled those observed in the control group and in individual control participants. Because NB showed more novelty responses in the right hippocampus than control participants, we speculated that the dorsal hippocampal commissure, which connects both structures across hemispheres, might play an important role in enabling NB's preserved recollection abilities in the face of left-sided partial cortical de-afferentiation. Indeed, recent structural neuroimaging evidence obtained with diffusion tensor imaging provides support for a role of this commissure in recognition-memory performance (Postans et al. 2019). We note that additional analyses in 
our study on NB also revealed intact novelty responses in left sided MTL structures that provide neuroanatomical input to the hippocampus, including in remaining tissue of perirhinal cortex and in the surgically spared parahippocampal cortex. As such, our fMRI findings in NB point to multiple pathways that could support spared hippocampal functioning in the face of impaired (but not completely absent) perirhinal cortex functioning and partial cortical de-afferentiation.

\subsection{Selective familiarity impairments can be observed in other cases}

Although the pattern of behavioural performance revealed in NB remains rare, selective familiarity impairments with intact recollection have been documented in a small number of subsequent studies that were conducted in other individuals with lesions that affected the MTL with similar patterns of sparing. One of these studies came from our group and was motivated by the observation that, during her pre-surgical clinical assessment, NB reported experiencing déjà vu during the aura of her seizures. Déjà vu is characterized as an impression of familiarity that is experienced as subjectively inappropriate (wrong), and it is typically considered to be a symptom that points to seizure origin in medial aspects of the temporal lobe (Gloor et al. 1982; Bancaud et al. 1994; Vignal et al. 2007; Guedj et al. 2010). Anecdotal observations suggest that these subjectively inappropriate feelings of familiarity are often initially tied to specific objects and then spread to other aspects of the visual environment during the aura ( $\mathrm{O}^{\prime}$ Connor and Moulin, 2008; Martin et al. 2012). Neuroimaging research has revealed that the presence of seizure-related déjà vu in temporal lobe epilepsy is associated with persistent hypometabolism in perirhinal and/or entorhinal cortex but not the hippocampus (Guedj et al. 2010). Against this background, we examined in our study whether patients suffering from unilateral temporal 
lobe epilepsy in combination with déjà vu as part of their seizure profile might display selective impairments in familiarity assessment (prior to any surgery) similar to those we observed postsurgically in NB (Martin et al. 2012). We administered a recognition-memory task that involved an RK procedure and categorized scenes that could primarily be distinguished based on the objects they contained. This task did indeed reveal deficits in familiarity-based discrimination with intact recollection in patients with déjà vu as compared to control participants. By contrast, patients with unilateral temporal lobe epilepsy but without déjà vu exhibited broader impairments that affected the accuracy of both familiarity and recollection on this task. In line with this pattern of results, a second experiment also revealed that patients with déjà vu could still successfully engage recollection to counteract experimentally induced feelings of familiarity on an exclusion task that required avoiding endorsement of repeated lures at test as targets. By contrast, the other group of patients showed impairments on this measure of performance. Importantly, MR-based volumetric assessment of MTL structures revealed more focal volume reductions that appeared to be centered on rhinal cortex in patients with déjà vu, which contrasted with the broader volume reductions that were present in patients without déjà vu. In more recent follow-up work that we conducted in patients who experienced déjà vu in relation to seizures of bilateral medial temporal lobe origin, however, we found no evidence for preserved recollection on these tasks. This evidence suggests that selective familiarity impairments might only emerge under circumstances in which lesions predominantly affect MTL functioning in one cerebral hemisphere (Martin et al. 2019).

Selective impairments in familiarity assessment with intact recollection have also been described in another neuropsychological case study of an individual with temporal lobe 
epilepsy, MR, in whom this condition resulted from the presence of a small cavernoma in the left MTL (Brandt et al. 2016). Although no volumetric measurements were provided, visual inspection of MR's anatomical MRI suggests that this cavernoma selectively affected the structural integrity of left entorhinal cortex. It is interesting to note that MR also reported déjà vu during the aura of her seizures (Brandt et al. 2018). Experimentally, MR's recognition memory was examined using an RK paradigm in four separate experiments that probed performance using words, pseudowords, famous faces, and faces unknown to MR prior to testing, respectively. Similar to NB, she exhibited impairments in familiarity-based discrimination together with intact recollection for verbal stimuli but not for faces. However, whereas NB's familiarity impairment was also observed when pronounceable non-words were employed as stimuli, MR's performance appeared to be normal under such experimental conditions. One possible explanation of this discrepancy in behavioural findings across patients relates to lesion extent; specifically, the discrepancy may reflect the fact that NB's lesion also encompasses aspects of anterior lateral temporal cortex. In a fifth experiment designed to examine the effect of MR's rhinal cortex lesion on non-declarative memory functioning, Brandt et al. (2016) found an abnormal conceptual priming effect, which the authors interpreted as evidence for a broader role of rhinal cortex in semantic processing (see Section 4.0 for further discussion).

A final set of findings that is relevant for the current discussion concerns behavioural and structural neuroimaging findings in older adults with genetic predisposition for developing neurodegenerative disease. Evidence from histological and neuroimaging research in individuals at the earliest stage of Alzheimer's disease point to a region at the border of 
entorhinal and perirhinal cortex as the first cortical structure to show neuropathological changes (Braak and Braak, 1991; Gómez-Isla et al. 1996). Thus, individuals who are at particularly high risk for developing Alzheimer's disease, such as carriers of the APOE $\varepsilon 4$ allele, may show impairments in familiarity prior to any other cognitive decline, including any decline in episodic recollection that is typically associated with full disease expression. Schoemaker et al. (2016) tested this possibility using a source memory task that required older adults to retrieve specific information about encoding context of items during the study phase (i.e., the colour in which an item were presented) or indicate recognition in the absence of source recollection. In such a task, successful retrieval of episodic source details is taken to reflect accuracy of recollection, whereas recognition of a prior item encounter in the absence of successful source memory is considered to be a marker of familiarity assessment (see Section 3.1 for discussion of drawbacks of this approach). Results revealed a significant impairment in familiarity-based discrimination with intact recollection for APOE $\varepsilon 4$ carriers, relative to noncarriers. Importantly, familiarity-based discrimination performance was also found to be significantly correlated with MR-based volumetric assessments of the integrity of entorhinal and perirhinal cortices in APOE $\varepsilon 4$ carriers (Schoemaker et al. 2017).

The studies reviewed here converge with the findings we reported for NB in indicating that anterior medial temporal lobe lesions with hippocampal sparing can produce selective impairments in familiarity-based discrimination. Recent neuropsychological data from another extensive case study (in patient JMG) suggest, however, that this pattern of memory impairment may not be ubiquitously observed in association with MTL lesions that spare hippocampal tissue (Lacot et al. 2017). Given the complexity of JMG's lesion, which affected 
MTL structures bilaterally, caution is required when making any direct comparisons with case NB. Nevertheless, because JMG's performance differed substantially depending on whether familiarity and recollection were probed with objects or with scenes, findings from both cases converge in pointing to stimulus material as an important factor that determines whether recognition memory will be impaired or preserved with MTL lesions (see Bird, 2017, for review of additional evidence from lesion research in humans).

\subsection{Implications and Conclusions}

The body of research we reviewed here provides converging evidence from multiple sources indicating that a focal temporal-lobe lesion with hippocampal sparing can affect familiarity assessment without having a negative impact on recollection. We presented six sets of findings from our single case study in NB that characterize this rare behavioural pattern of impaired and preserved memory functioning, and that also shed first light on associated neural mechanisms reflected in task-related fMRI BOLD responses in the MTL. Another set of findings we reviewed covered follow-up work conducted in a small number cases with similar lesion profiles that leads to the same general conclusion. The latter evidence suggests that the lessons that can be learned from case NB speak to principles of brain organization that are not unique to this individual.

Our research was guided by the dual-process model of recognition memory and the proposal that the hippocampus plays a necessary role in the relational binding of items to episodic contexts, and that item-based memory itself does not require hippocampal contributions but relies on perirhinal cortex (Aggleton and Brown, 1999; Davachi, 2006; 
Eichenbaum et al. 2007; Mayes et al. 2007). We recognize that the surgical resection in NB was not restricted to left perirhinal cortex, but also affected other anterior temporal-lobe structures, including entorhinal cortex and anterolateral temporal cortex. We cannot rule out that removal of these other structures may have contributed to the observed selective impairments in familiarity assessment we have described in NB. Lesion research that followed up on our research in NB in other patients, however, has revealed similarly selective impairments in association with damage to perirhinal and/or entorhinal cortex, in combination with hippocampal sparing. These findings provide critical evidence to suggest, that damage to rhinal cortices is sufficient to produce deficits in familiarity assessment (Martin et al. 2012; Brandt et al. 2016, 2018; Schoemaker et al. 2016, 2017). In addition, there is substantial evidence from functional neuroimaging research, intracranial recordings, as well as lesion and recording studies in non-human species that implicates perirhinal cortex, and more recently entorhinal cortex, in item-based familiarity assessment. A comprehensive review of this literature, and a discussion of inconsistencies, is beyond the scope of the present paper (see Eichenbaum et al. 2007; Wixted et al. 2010; Yonelinas et al. 2010; Bastin et al. 2019, for review). To highlight the anatomical specificity of converging findings that have been obtained in other species, we point the reader to a body of lesion research in nonhuman primates that has implicated perirhinal as well as entorhinal cortex in performance on delayed matching to sample tasks for objects (with a hint that perirhinal cortex plays a larger role; see Murray et al. 2017, for review). A recent study in rodents provides converging evidence based on immediate early gene imaging with Arc at the cellular level. Probing familiarity-based recognition with a response deadline procedure (similar to our work in NB) in a recognition memory task that 
required delayed non-matching to sample for odors, the authors reported contributions of the deep layers of lateral entorhinal cortex and perirhinal cortex, but not of hippocampal subfields CA3 and CA1, to familiarity assessment (Atucha et al. 2017). When the task could be solved based on familiarity and recollection in the absence of a response deadline, by contrast, evidence for hippocampal subfield involvement could be observed. While the evidence that links both entorhinal and perirhinal cortex to item-based recognition memory is growing, an outstanding issue for future research is to determine how functional contributions of these two structures differ from each other. One pertinent finding from recent high-resolution neuroimaging research in humans is that (anterolateral) entorhinal cortex integrates location information into object representations (Yeung et al., 2019). Perirhinal cortex representations, by contrast, do not appear to carry such spatial information about items (see Connor and Knierim, 2017 for review of related research in other species).

From another perspective, one might argue that the findings that are of highest importance in case NB are those that speak to preserved memory functions in the face of her familiarity impairments, namely her intact recollection abilities in association with hippocampal sparing (see Clark and Maguire, 2016, for the importance of studying preservation in memory disorders). As discussed in section 3.6, our fMRI findings in NB point to multiple pathways that could support spared hippocampal functioning in the face of partial cortical de-afferentiation and impaired, but not completely absent perirhinal cortex functioning.

How is it possible that recognition-memory probes might trigger intact recollection processes and experiences, while compromising item-based discrimination? We have previously speculated that the fidelity of item representations needed to prompt recollection 
may be lower than that which is required for fine grained familiarity-based discriminations (Martin et al. 2012). If a perirhinal representation of items is critical for prompting recollection, a pattern of selective familiarity impairments may only be observed if damage to rhinal cortices is partial (with unilateral damage or perhaps partial damage in both hemispheres). This appears to be the case for all reported cases with selective familiarity impairments for whom sufficiently precise lesion documentation is available, including NB (see Section 3.7). Another scenario to consider is that recollection may not just be triggered by item but also by context information. There is behavioural evidence from recognition memory experiments suggesting that the availability of context information can boost recollection accuracy (e.g., Gruppuso et al. 2007; Ameen-Ali et al. 2017). Notably, representation of context has been proposed to be carried by a network of regions that is rooted in parahippocampal cortex (Bar and Aminoff, 2003;

Eichenbaum et al. 2007; Ranganath and Ritchey, 2012; Aminoff et al. 2013), another MTL structure that is spared in NB, and that may still provide input to the hippocampus through relay in remaining tissue in left perirhinal and entorhinal cortex (Suzuki and Amaral, 1994; Schröder et al. 2015). A complete understanding of how recognition-memory probes might trigger intact recollection, while compromising item-based discrimination, will likely require computational work that takes into consideration anatomical as well as functional properties of the MTL.

Strikingly, we observed in multiple experiments that NB's overall discrimination accuracy was not affected by her lesion when both familiarity assessment and recollection could be brought to bear on the memory task at hand. This pattern of behaviour suggests that recollection plays a more dominant role in recognizing prior occurrence for NB than for control 
participants, perhaps as a result of compensation. At the anatomical level, the stronger reliance on recollection may go hand in hand with an increased reliance on hippocampal over perirhinal memory signals. Indeed, it has previously been suggested that signals from both structures compete with each other when recognition-memory decisions are being made, and that lesions affecting one structure (but not the other) perturb the normal balance in this competition (Baxter and Murray, 2001; see Kapur, 2011, for discussion in relation to case NB). That we observed increased differential activation in NB's hippocampus in our fMRI study provides some support for this interpretation. Given that this increase in activation was not examined during performance of a recognition memory task, this evidence must, however, be considered indirect when trying to understand the mechanisms that underlie NB's memory decisions.

The notion that NB's lesion has led to an increased reliance on recollection also raises interesting questions as to how such a change in behaviour is triggered. If it is a compensatory response, does it reflect a targeted, strategic effort in situations that demand a recognition response? Assuming that strategic compensation requires an awareness of deficit, we are reluctant to interpret our results in this manner. As mentioned in our case description, NB does not subjectively perceive her memory functioning to be impaired. In fact, at a conceptual level, it is not clear to us whether familiarity could ever be expected to be subjectively perceived as abnormal (i.e., as a deficit). Whittlesea and colleagues (1997) have highlighted in their work that spontaneous experiences of familiarity typically occur in contexts in which they are unexpected (“Why do strangers feel familiar, but friends don't?”). Detecting changes in phenomenological personal experience following brain damage is likely going to be more difficult, if not impossible, when such experience pertains to the unexpected. 
Although our findings in NB offer compelling evidence that a temporal-lobe lesion with perirhinal involvement and hippocampal sparing can impair familiarity assessment in conjunction with intact recollection, these findings do not necessarily imply that the functional specialization of both structures is best captured with reference the dual-process model of recognition-memory. Indeed, is has been questioned whether an account of this functional specialization requires any reference to a dedicated role of the MTL in declarative memory at all (e.g., Murray and Bussey, 1999; Murray et al. 2007; Graham et al. 2010; Maguire and Mullally, 2013; Shohamy and Turk-Browne, 2013; Cowell et al. 2019). One prominent idea in this literature is the notion that the hippocampus plays a dedicated role in scene processing and construction that can be contrasted with that of perirhinal cortex in object processing. In general terms, evidence in favor of such models has come from studies showing MTL involvement in tasks without any declarative memory demands, including but not limited to tasks of implicit memory and perceptual discrimination. For perirhinal cortex, specifically, there have been a number of functional neuroimaging and patient studies in humans suggesting that perirhinal cortex plays a role in conceptual priming on tasks that do not require explicit reference to any recent experimental encounter (O'Kane et al. 2005; Voss et al. 2009; Wang et al. 2010; Dew and Cabeza, 2011; Heusser et al. 2013; Wang et al. 2014). Indeed, a role for this structure in object processing has even been revealed in paradigms that do not include any experimental study phase (Bruffaerts et al. 2013; Clarke and Tyler, 2014; Wright et al. 2015; Martin et al. 2018b; Liuzzi et al. 2019). In the latter studies, which again were based on functional neuroimaging as well as lesion research, it has been shown that perirhinal cortex carries information that is of particular relevance for making fine-grained distinctions among 
objects or object concepts with high feature overlap based on either perceptual or conceptual features. Taken together, many of these findings converge in supporting an account of perirhinal cortex function that emphasizes the nature of the content that this structure represents over distinctions among different memory processes (see Cowell et al. 2019).

Our research on NB has almost exclusively focused on recognition memory tasks that made reference to a recent experimentally controlled study episode. As such they do not directly address whether her lesion also affects processing of objects or object concepts more broadly. We note, however, that our experiment on judgments of cumulative lifetime experience in NB did not require such reference, and that it also revealed sensitivity of her performance to degree of conceptual feature overlap (see Sections 3.4 and 3.5). As indicated previously, these aspects of our data hint that NB might even exhibit broader difficulties in making fine-grained distinctions between object concepts, beyond tasks that require making reference to recent occurrence of such object concepts. Although a speculation for NB, we note that Wright et al. (2015) observed deficits in processing object concepts that were highly sensitivity to feature overlap (i.e., confusability) in patients with focal temporal lobe lesions on tasks of naming and picture matching. Critically, across individuals in this group, the degree of deficits could be linked to lesion overlap in perirhinal cortex. In this study, however, recognition memory was not examined. As such establishing a link between behavioural deficits in both familiarity assessment and processing of object concepts in task context without explicit memory demands on the one hand, and perirhinal cortex dysfunction on the other, remains an important avenue for future human lesion research. Such research will be of critical importance 
for understanding the organization of the MTL in a way that accounts for contributions to both recognition memory and cognition more broadly.

Acknowledgements: We thank NB for eagerly dedicating so much of her time to the research described herein. We also thank Drs. Ben Bowles, Devin Duke, and Seyed Mirsattari for their contributions to much of the primary research reviewed here.

Funding Sources: This work was supported by the Canadian Institutes of Health Research under Grant MOP93644 and by the Natural Sciences and Engineering Research Council of Canada under Grant RGPIN-2018-05770 to SK.

Declarations of interest: none

\section{References}

Aggleton, J. P., \& Brown, M. W. (1999). Episodic memory, amnesia, and the hippocampalanterior thalamic axis. Behavioral and Brain Sciences, 22(3), 425-444. https://doi.org/10.1017/S0140525X99002034

Aggleton, J. P., Vann, S. D., Denby, C., Dix, S., Mayes, A. R., Roberts, N., \& Yonelinas, A. P. (2005). Sparing of the familiarity component of recognition memory in a patient with hippocampal pathology. Neuropsychologia, 43(12), 1810-1823. https://doi.org/10.1016/i.neuropsychologia.2005.01.019

Aggleton, J. P. (2012). Multiple anatomical systems embedded within the primate medial temporal lobe: implications for hippocampal function. Neuroscience \& Biobehavioral Reviews, 36(7), 1579-1596. https://doi.org/10.1016/j.neubiorev.2011.09.005

Aggleton, J. P., Wright, N. F., Vann, S. D., \& Saunders, R. C. (2012). Medial temporal lobe projections to the retrosplenial cortex of the macaque monkey. Hippocampus, 22(9), 18831900. https://doi.org/10.1002/hipo.22024

Aly, M., Knight, R. T., \& Yonelinas, A. P. (2010). Faces are special but not too special: Spared face recognition in amnesia is based on familiarity. Neuropsychologia, 48(13), 3941-3948. https://doi.org/10.1016/j.neuropsychologia.2010.09.005 
Aly, M., \& Ranganath, C. (2018). New perspectives on the hippocampus and memory. Neuroscience Letters, 680, 1. https://doi.org/10.1016/i.neulet.2018.05.047

Ameen-Ali, K. E., Norman, L. J., Eacott, M. J., \& Easton, A. (2017). Incidental context information increases recollection. Learning \& Memory, 24(3), 136-139.

https://doi.org/10.1101//m.042622.116

Aminoff, E. M., Kveraga, K., \& Bar, M. (2013). The role of the parahippocampal cortex in cognition. Trends in Cognitive Sciences, 17(8), 379-390.

https://doi.org/10.1016/i.tics.2013.06.009

Atucha, E., Karew, A., Kitsukawa, T., \& Sauvage, M. M. (2017). Recognition memory: Cellular evidence of a massive contribution of the LEC to familiarity and a lack of involvement of the hippocampal subfields CA1 and CA3. Hippocampus, 27(10), 1083-1092.

https://doi.org/10.1002/hipo.22754

Bancaud, J., Brunet-Bourgin, F., Chauvel, P., Halgren, E., \& This paper is dedicated to the memory of Jean Bancaud. (1994). Anatomical origin of déjà vu and vivid 'memories' in human temporal lobe epilepsy. Brain, 117(1), 71-90.

https://doi.org/10.1093/brain/117.1.71

Bar, M., \& Aminoff, E. (2003). Cortical analysis of visual context. Neuron, 38(2), 347-358. https://doi.org/10.1016/S0896-6273(03)00167-3

Basile, B. M., \& Hampton, R. R. (2013). Recognition errors suggest fast familiarity and slow recollection in rhesus monkeys. Learning \& Memory, 20(8), 431-437. https://doi.org/10.1101//m.029223.112

Bastin, C., \& Besson, G. (2017). Impaired familiarity in individuals at risk for Alzheimer's disease: Commentary on Schoemaker et al.(2016). Alzheimer's \& Dementia: Diagnosis, Assessment \& Disease Monitoring, 6, 60-61. https://doi.org/10.1016/i.dadm.2016.11.008

Bastin, C., Besson, G., Simon, J., Delhaye, E., Geurten, M., Willems, S., \& Salmon, E. (2019). An Integrative Memory model of recollection and familiarity to understand memory deficits. Behavioral and Brain Sciences, 1-66. https://doi.org/10.1017/S0140525X19000621

Baxter, M. G., \& Murray, E. A. (2001). Opposite relationship of hippocampal and rhinal cortex damage to delayed nonmatching-to-sample deficits in monkeys. Hippocampus, 11(1), 6171. https://doi.org/10.1002/1098-1063(2001)11:1<61::AID-HIPO1021>3.0.CO;2-Z

Besson, G., Ceccaldi, M., Tramoni, E., Felician, O., Didic, M., \& Barbeau, E. J. (2015). Fast, but not slow, familiarity is preserved in patients with amnestic mild cognitive impairment. Cortex, 65, 36-49. https://doi.org/10.1016/j.cortex.2014.10.020

Bird, C. M. (2017). The role of the hippocampus in recognition memory. Cortex, 93, 155-165. https://doi.org/10.1016/i.cortex.2017.05.016 
Bohbot, V. D., Kalina, M., Stepankova, K., Spackova, N., Petrides, M., \& Nadel, L. Y. N. N. (1998). Spatial memory deficits in patients with lesions to the right hippocampus and to the right parahippocampal cortex. Neuropsychologia, 36(11), 1217-1238.

https://doi.org/10.1016/S0028-3932(97)00161-9

Boldini, A., Russo, R., \& Avons, S. E. (2004). One process is not enough! A speed-accuracy tradeoff study of recognition memory. Psychonomic Bulletin \& Review, 11(2), 353-361. https://doi.org/10.3758/BF03196582

Bowles, B., Crupi, C., Mirsattari, S. M., Pigott, S. E., Parrent, A. G., Pruessner, J. C., Yonelinas A.P., \& Köhler, S. (2007). Impaired familiarity with preserved recollection after anterior temporal-lobe resection that spares the hippocampus. Proceedings of the National Academy of Sciences, 104(41), 16382-16387. https://doi.org/10.1073/pnas.0705273104

Bowles, B., Crupi, C., Pigott, S., Parrent, A., Wiebe, S., Janzen, L., \& Köhler, S. (2010). Double dissociation of selective recollection and familiarity impairments following two different surgical treatments for temporal-lobe epilepsy. Neuropsychologia, 48(9), 2640-2647. https://doi.org/10.1016/i.neuropsychologia.2010.05.010

Bowles, B., O'Neil, E. B., Mirsattari, S. M., Poppenk, J., \& Köhler, S. (2011). Preserved hippocampal novelty responses following anterior temporal-lobe resection that impairs familiarity but spares recollection. Hippocampus, 21(8), 847-854.

https://doi.org/10.1002/hipo.20800

Bowles, B., Duke, D., Rosenbaum, R. S., McRae, K., \& Köhler, S. (2016). Impaired assessment of cumulative lifetime familiarity for object concepts after left anterior temporal-lobe resection that includes perirhinal cortex but spares the hippocampus. Neuropsychologia, 90, 170-179. https://doi.org/10.1016/j.neuropsychologia.2016.06.035

Braak, H., \& Braak, E. (1991). Neuropathological stageing of Alzheimer-related changes. Acta Neuropathologica, 82(4), 239-259. https://doi.org/10.1007/BF00308809

Brandt, K. R., Eysenck, M. W., Nielsen, M. K., \& von Oertzen, T. J. (2016). Selective lesion to the entorhinal cortex leads to an impairment in familiarity but not recollection. Brain and Cognition, 104, 82-92. https://doi.org/10.1016/j.bandc.2016.02.005

Brandt, K. R., Conway, M. A., James, A., \& von Oertzen, T. J. (2018). Déjà vu and the entorhinal cortex: dissociating recollective from familiarity disruptions in a single case patient. Memory, 1-10. https://doi.org/10.1080/09658211.2018.1543436

Bruffaerts, R., Dupont, P., Peeters, R., De Deyne, S., Storms, G., \& Vandenberghe, R. (2013). Similarity of fMRI activity patterns in left perirhinal cortex reflects semantic similarity between words. Journal of Neuroscience, 33(47), 18597-18607. https://doi.org/10.1523/JNEUROSCI.1548-13.2013 
Cipolotti, L., Bird, C., Good, T., Macmanus, D., Rudge, P., \& Shallice, T. (2006). Recollection and familiarity in dense hippocampal amnesia: A case study. Neuropsychologia, 44(3), 489-506. https://doi.org/10.1016/i.neuropsychologia.2005.05.014

Clark, I. A., \& Maguire, E. A. (2016). Remembering preservation in hippocampal amnesia. Annual Review of Psychology, 67, 51-82. https://doi.org/10.1146/annurev-psych$\underline{122414-033739}$

Clarke, A., \& Tyler, L. K. (2014). Object-specific semantic coding in human perirhinal cortex. Journal of Neuroscience, 34(14), 4766-4775. https://doi.org/10.1523/JNEUROSCI.2828-13.2014

Cohn, M., McAndrews, M. P., \& Moscovitch, M. (2009). Associative reinstatement: a novel approach to assessing associative memory in patients with unilateral temporal lobe excisions. Neuropsychologia, 47(13), 2989-2994. https://doi.org/10.1016/j.neuropsychologia.2009.06.029

Connor, C. E., \& Knierim, J. J. (2017). Integration of objects and space in perception and memory. Nature Neuroscience, 20(11), 1493. https://doi.org/10.1038/nn.4657

Cowell, R. A., Barense, M. D., \& Sadil, P. S. (2019). A roadmap for understanding memory: Decomposing cognitive processes into operations and representations. eNeuro, ENEURO0122. https://doi.org/10.1523/ENEURO.0122-19.2019

Cree, G. S., \& McRae, K. (2003). Analyzing the factors underlying the structure and computation of the meaning of chipmunk, cherry, chisel, cheese, and cello (and many other such concrete nouns). Journal of Experimental Psychology: General, 132(2), 163.

Davachi, L. (2006). Item, context and relational episodic encoding in humans. Current Opinion in Neurobiology, 16(6), 693-700. https://doi.org/10.1016/j.conb.2006.10.012

Despouy, E., Curot, J., Deudon, M., Gardy, L., Denuelle, M., Sol, J. C., Lotterie, J-A., Valton, L., \& Barbeau, E. J. (2019). A Fast Visual Recognition Memory System in Humans Identified Using Intracerebral ERP. Cerebral Cortex. https://doi.org/10.1093/cercor/bhz287

Dew, I. T., \& Cabeza, R. (2011). The porous boundaries between explicit and implicit memory: behavioral and neural evidence. Annals of the New York Academy of Sciences, 1224(1), 174190. https://doi.org/10.1111/j.1749-6632.2010.05946.x

Dewhurst, S. A., Holmes, S. J., Brandt, K. R., \& Dean, G. M. (2006). Measuring the speed of the conscious components of recognition memory: Remembering is faster than knowing. Consciousness and Cognition, 15(1), 147-162. https://doi.org/10.1016/j.concog.2005.05.002 
Diana, R. A., Yonelinas, A. P., \& Ranganath, C. (2007). Imaging recollection and familiarity in the medial temporal lobe: a three-component model. Trends in Cognitive Sciences, 11(9), 379386. https://doi.org/10.1016/i.tics.2007.08.001

Duke, D., Martin, C. B., Bowles, B., McRae, K., \& Köhler, S. (2017). Perirhinal cortex tracks degree of recent as well as cumulative lifetime experience with object concepts. Cortex, 89, 61-70. https://doi.org/10.1016/j.cortex.2017.01.015

Dunn, J. C., \& Kirsner, K. (2003). What can we infer from double dissociations? Cortex 39(1) 1-7. https://doi.org/10.1016/S0010-9452(08)70070-4

Düzel, E., Yonelinas, A. P., Mangun, G. R., Heinze, H. J., \& Tulving, E. (1997). Event-related brain potential correlates of two states of conscious awareness in memory. Proceedings of the National Academy of Sciences, 94(11), 5973-5978.

https://doi.org/10.1073/pnas.94.11.5973

Eichenbaum, H., Yonelinas, A. P., \& Ranganath, C. (2007). The medial temporal lobe and recognition memory. Annual Review of Neuroscience., 30, 123-152. https://doi.org/10.1146/annurev.neuro.30.051606.094328

Eichenbaum, H. (2013). What HM taught us. Journal of Cognitive Neuroscience, 25(1), 14-21. https://doi.org/10.1162/jocn_a_00285

Eichenbaum, H. (2017). Memory: organization and control. Annual Review of Psychology, 68, 19-45. https://doi.org/10.1146/annurev-psych-010416-044131

Gloor, P., Olivier, A., Quesney, L., Andermann, F., \& Horowitz, S. (1982). The role of limbic system in experiential phenomena of temporal lobe epilepsy. Annals of Neurology, 12(2), 129-144. https://doi.org/10.1002/ana.410120203

Gold, J. J., Smith, C. N., Bayley, P. J., Shrager, Y., Brewer, J. B., Stark, C. E., Hopkins, R.O., \& Squire, L. R. (2006). Item memory, source memory, and the medial temporal lobe: Concordant findings from $\mathrm{fMRI}$ and memory-impaired patients. Proceedings of the National Academy of Sciences, 103(24), 9351-9356. https://doi.org/10.1073/pnas.0602716103

Gómez-Isla, T., Price, J. L., McKeel Jr, D. W., Morris, J. C., Growdon, J. H., \& Hyman, B. T. (1996). Profound loss of layer II entorhinal cortex neurons occurs in very mild Alzheimer's disease. Journal of Neuroscience, 16(14), 4491-4500. https://doi.org/10.1523/JNEUROSCl.16-14-04491.1996

Graham, K. S., Barense, M. D., \& Lee, A. C. (2010). Going beyond LTM in the MTL: a synthesis of neuropsychological and neuroimaging findings on the role of the medial temporal lobe in memory and perception. Neuropsychologia, 48(4), 831-853. https://doi.org/10.1016/j.neuropsychologia.2010.01.001 
Gruppuso, V., Lindsay, D. S., \& Masson, M. E. (2007). I'd know that face anywhere!. Psychonomic Bulletin \& Review, 14(6), 1085-1089. https://doi.org/10.3758/BF03193095

Guedj, E., Aubert, S., McGonigal, A., Mundler, O., \& Bartolomei, F. (2010). Deja-vu in temporal lobe epilepsy: metabolic pattern of cortical involvement in patients with normal brain MRI. Neuropsychologia, 48(7), 2174-2181. https://doi.org/10.1016/j.neuropsychologia.2010.04.009

Heusser, A. C., Awipi, T., \& Davachi, L. (2013). The ups and downs of repetition: Modulation of the perirhinal cortex by conceptual repetition predicts priming and long-term memory. Neuropsychologia, 51(12), 2333-2343. https://doi.org/10.1016/j.neuropsychologia.2013.04.018

Hintzman, D. L., \& Curran, T. (1994). Retrieval dynamics of recognition and frequency judgments: Evidence for separate processes of familiarity and recall. Journal of Memory and Language, 33(1), 1-18. https://doi.org/10.1006/imla.1994.1001

Hintzman, D. L. (2004). Judgment of frequency versus recognition confidence: Repetition and recursive reminding. Memory \& Cognition, 32(2), 336-350. https://doi.org/10.3758/BF03196863

Holdstock, J. S., Parslow, D. M., Morris, R. G., Fleminger, S., Abrahams, S., Denby, C., Montaldi, D., \& Mayes, A. R. (2008). Two case studies illustrating how relatively selective hippocampal lesions in humans can have quite different effects on memory. Hippocampus, 18(7), 679-691. https://doi.org/10.1002/hipo.20427

Kahn, I., Davachi, L., \& Wagner, A. D. (2004). Functional-neuroanatomic correlates of recollection: implications for models of recognition memory. Journal of Neuroscience, 24(17), 4172-4180. https://doi.org/10.1523/JNEUROSCI.0624-04.2004

Kafkas, A., Migo, E. M., Morris, R. G., Kopelman, M. D., Montaldi, D., \& Mayes, A. R. (2017). Material specificity drives medial temporal lobe familiarity but not hippocampal recollection. Hippocampus, 27(2), 194-209. https://doi.org/10.1002/hipo.22683

Kapur, N. (2011). Paradoxical functional facilitation and recovery in neurological and psychiatric conditions (pp 40-73). In: The paradoxical brain (Ed. N Kapur). Cambridge: Cambridge University Press.

Kivisaari, S. L., Monsch, A. U., \& Taylor, K. I. (2013). False positives to confusable objects predict medial temporal lobe atrophy. Hippocampus, 23(9), 832-841.

https://doi.org/10.1002/hipo.22137

Köhler, S., Danckert, S., Gati, J. S., \& Menon, R. S. (2005). Novelty responses to relational and non-relational information in the hippocampus and the parahippocampal region: $A$ 
comparison based on event-related fMRI. Hippocampus, 15(6), 763-774. https://doi.org/10.1002/hipo.20098

Kumaran, D., \& Maguire, E. A. (2006). An unexpected sequence of events: mismatch detection in the human hippocampus. PLoS Biology, 4(12), e424. https://doi.org/10.1371/journal.pbio.0040424

Lacot, E., Vautier, S., Kőhler, S., Pariente, J., Martin, C. B., Puel, M., Lotterie, J.A., \& Barbeau, E. J. (2017). Familiarity and recollection vs representational models of medial temporal lobe structures: A single-case study. Neuropsychologia, 104, 76-91. https://doi.org/10.1016/i.neuropsychologia.2017.07.032

Lavenex, P., \& Amaral, D. G. (2000). Hippocampal-neocortical interaction: A hierarchy of associativity. Hippocampus, 10(4), 420-430. https://doi.org/10.1002/10981063(2000)10:4<420::AID-HIPO8>3.0.CO;2-5

Lee, T. M., Yip, J. T., \& Jones-Gotman, M. (2002). Memory deficits after resection from left or right anterior temporal lobe in humans: a meta-analytic review. Epilepsia, 43(3), 283-291. https://doi.org/10.1046/i.1528-1157.2002.09901.x

Libby, L. A., Ekstrom, A. D., Ragland, J. D., \& Ranganath, C. (2012). Differential connectivity of perirhinal and parahippocampal cortices within human hippocampal subregions revealed by high-resolution functional imaging. Journal of Neuroscience, 32(19), 6550-6560. https://doi.org/10.1523/JNEUROSCI.3711-11.2012

Liuzzi, A. G., Bruffaerts, R., \& Vandenberghe, R. (2019). The medial temporal written word processing system. Cortex, 119, 287-300. https://doi.org/10.1016/i.cortex.2019.05.002

Mandler, G. (1980). Recognizing: The judgment of previous occurrence. Psychological Review, 87(3), 252. http://dx.doi.org/10.1037/0033-295X.87.3.252

Manns, J. R., Hopkins, R. O., Reed, J. M., Kitchener, E. G., \& Squire, L. R. (2003). Recognition memory and the human hippocampus. Neuron, 37(1), 171-180. https://doi.org/10.1016/S0896-6273(02)01147-9

Martin, C. B., Bowles, B., Mirsattari, S. M., \& Köhler, S. (2011). Selective familiarity deficits after left anterior temporal-lobe removal with hippocampal sparing are material specific. Neuropsychologia, 49(7), 1870-1878. https://doi.org/10.1016/i.neuropsychologia.2011.03.012

Martin, C. B., Mirsattari, S. M., Pruessner, J. C., Pietrantonio, S., Burneo, J. G., Hayman-Abello, B., \& Köhler, S. (2012). Déjà vu in unilateral temporal-lobe epilepsy is associated with selective familiarity impairments on experimental tasks of recognition memory. Neuropsychologia, 50(13), 2981-2991. https://doi.org/10.1016/j.neuropsychologia.2012.07.030 
Martin, C. B., McLean, D. A., O'Neil, E. B., \& Köhler, S. (2013). Distinct familiarity-based response patterns for faces and buildings in perirhinal and parahippocampal cortex. Journal of Neuroscience, 33(26), 10915-10923. https://doi.org/10.1523/JNEUROSCI.0126-13.2013

Martin, C. B., Sullivan, J. A., Wright, J., \& Köhler, S. (2018a). How landmark suitability shapes recognition memory signals for objects in the medial temporal lobes. Neurolmage, 166, 425-436. https://doi.org/10.1016/j.neuroimage.2017.11.004

Martin, C. B., Douglas, D., Newsome, R. N., Man, L. L., \& Barense, M. D. (2018b). Integrative and distinctive coding of visual and conceptual object features in the ventral visual stream. Elife, 7, e31873. https://doi.org/10.7554/eLife.31873

Martin, C. B., Mirsattari, S. M., Pruessner, J. C., Burneo, J. G., Hayman-Abello, B., \& Köhler, S. (2019). Relationship between déjà vu experiences and recognition-memory impairments in temporal-lobe epilepsy. Memory, 1-11. https://doi.org/10.1080/09658211.2019.1643891

Mayes, A. R., Holdstock, J. S., Isaac, C. L., Hunkin, N. M., \& Roberts, N. (2002). Relative sparing of item recognition memory in a patient with adult-onset damage limited to the hippocampus. Hippocampus, 12(3), 325-340. https://doi.org/10.1002/hipo.1111

Mayes, A., Montaldi, D., \& Migo, E. (2007). Associative memory and the medial temporal lobes. Trends in Cognitive Sciences, 11(3), 126-135.

https://doi.org/10.1016/j.tics.2006.12.003

Milner, B. (1972). Disorders of learning and memory after temporal lobe lesions in man. Neurosurgery, 19(CN_suppl_1), 421-446. https://doi.org/10.1093/neurosurgery/19.CN suppl 1.421

Montaldi, D., Spencer, T. J., Roberts, N., \& Mayes, A. R. (2006). The neural system that mediates familiarity memory. Hippocampus, 16(5), 504-520. https://doi.org/10.1002/hipo.20178

Moreno-Martínez, F. J., Montoro, P. R., \& Rodríguez-Rojo, I. C. (2014). Spanish norms for age of acquisition, concept familiarity, lexical frequency, manipulability, typicality, and other variables for 820 words from 14 living/nonliving concepts. Behavior Research Methods, 46(4), 1088-1097. https://doi.org/10.3758/s13428-013-0435-x

Moscovitch, M., Cabeza, R., Winocur, G., \& Nadel, L. (2016). Episodic memory and beyond: the hippocampus and neocortex in transformation. Annual Review of Psychology, 67, 105-134. https://doi.org/10.1146/annurev-psych-113011-143733

Maguire, E. A., \& Mullally, S. L. (2013). The hippocampus: a manifesto for change. Journal of Experimental Psychology: General, 142(4), 1180. https://doi.org/10.1037/a0033650

Murray, E. A., \& Bussey, T. J. (1999). Perceptual-mnemonic functions of the perirhinal cortex. Trends in Cognitive Sciences, 3(4), 142-151. https://doi.org/10.1016/S1364$\underline{6613(99) 01303-0}$ 
Murray, E. A., Bussey, T. J., \& Saksida, L. M. (2007). Visual perception and memory: a new view of medial temporal lobe function in primates and rodents. Annual Review of Neuroscience., 30, 99-122. https://doi.org/10.1146/annurev.neuro.29.051605.113046

Murray, E. A., Wise, S. P., \& Graham, K. S. (2017). The evolution of memory systems: ancestors, anatomy, and adaptations. Oxford University Press.

O'Connor, A. R., \& Moulin, C. J. (2008). The persistence of erroneous familiarity in an epileptic male: Challenging perceptual theories of déjà vu activation. Brain and Cognition, 68(2), 144-147. https://doi.org/10.1016/j.bandc.2008.03.007

O'Kane, G., Insler, R. Z., \& Wagner, A. D. (2005). Conceptual and perceptual novelty effects in human medial temporal cortex. Hippocampus, 15(3), 326-332. https://doi.org/10.1002/hipo.20053

Parrent, A. G., \& Blume, W. T. (1999). Stereotactic amygdalohippocampotomy for the treatment of medial temporal lobe epilepsy. Epilepsia, 40(10), 1408-1416. https://doi.org/10.1111/i.1528-1157.1999.tb02013.x

Poppenk, J., Walia, G., Mclntosh, A. R., Joanisse, M. F., Klein, D., \& Köhler, S. (2008). Why is the meaning of a sentence better remembered than its form? An fMRI study on the role of novelty-encoding processes. Hippocampus, 18(9), 909-918. https://doi.org/10.1002/hipo.20453

Postans, M., Parker, G. D., Lundell, H., Ptito, M., Hamandi, K., Gray, W. P., Aggleton, J.P., Dyrby, T.B., Jones, D.K., \& Winter, M. (in press). Uncovering a Role for the Dorsal Hippocampal Commissure in Recognition Memory. Cerebral Cortex. http://doi.org/10.1093/cercor/bhz143

Ranganath, C., \& Ritchey, M. (2012). Two cortical systems for memory-guided behaviour. Nature Reviews Neuroscience, 13(10), 713. https://doi.org/10.1038/nrn3338

Reagh, Z. M., \& Ranganath, C. (2018). What does the functional organization of corticohippocampal networks tell us about the functional organization of memory? Neuroscience Letters, 680, 69-76. https://doi.org/10.1016/j.neulet.2018.04.050

Rosenbaum, R. S., Köhler, S., Schacter, D. L., Moscovitch, M., Westmacott, R., Black, S. E., Gao, F., \& Tulving, E. (2005). The case of KC: contributions of a memory-impaired person to memory theory. Neuropsychologia, 43(7), 989-1021. https://doi.org/10.1016/i.neuropsychologia.2004.10.007

Rosenbaum, R. S., Gilboa, A., \& Moscovitch, M. (2014). Case studies continue to illuminate the cognitive neuroscience of memory. Annals of the New York Academy of Sciences, 1316(1), 105-133. https://doi.org/10.1111/nyas.12467 
Rugg, M. D., Vilberg, K. L., Mattson, J. T., Sarah, S. Y., Johnson, J. D., \& Suzuki, M. (2012). Item memory, context memory and the hippocampus: fMRI evidence. Neuropsychologia, 50(13), 3070-3079. https://doi.org/10.1016/j.neuropsychologia.2012.06.004

Saling, M. M. (2009). Verbal memory in mesial temporal lobe epilepsy: beyond material specificity. Brain, 132(3), 570-582. https://doi.org/10.1093/brain/awp012

Schoemaker, D., Poirier, J., Escobar, S., Gauthier, S., \& Pruessner, J. (2016). Selective familiarity deficits in otherwise cognitively intact aging individuals with genetic risk for Alzheimer's disease. Alzheimer's \& Dementia: Diagnosis, Assessment \& Disease Monitoring, 2, 132-139. https://doi.org/10.1016/j.dadm.2015.11.007

Schoemaker, D., Poirier, J., Collins, D. L., Gauthier, S., \& Pruessner, J. C. (2017). Familiarity deficits in cognitively normal aging individuals with APOE $\varepsilon 4$ : A follow-up investigation of medial temporal lobe structural correlates. Alzheimer's \& Dementia: Diagnosis, Assessment \& Disease Monitoring, 9, 21-24. https://doi.org/10.1016/j.dadm.2017.05.008

Schröder, A., Gemballa, T., Ruppin, S., \& Wartenburger, I. (2012). German norms for semantic typicality, age of acquisition, and concept familiarity. Behavior Research Methods, 44(2), 380-394. https://doi.org/10.3758/s13428-011-0164-y

Schröder, T. N., Haak, K. V., Jimenez, N. I. Z., Beckmann, C. F., \& Doeller, C. F. (2015). Functional topography of the human entorhinal cortex. Elife, 4, e06738. https://doi.org/10.7554/eLife.06738

Scoville, W. B., \& Milner, B. (1957). Loss of recent memory after bilateral hippocampal lesions. Journal of Neurology, Neurosurgery, and Psychiatry, 20(1), 11. https://doi.org/10.1136/innp-2015-311092

Shohamy, D., \& Turk-Browne, N. B. (2013). Mechanisms for widespread hippocampal involvement in cognition. Journal of Experimental Psychology: General, 142(4), 1159. http://dx.doi.org/10.1037/a0034461

Smith, M. L. (1989). Memory disorders associated with temporal-lobe lesions. In F. Boller, \& Grafman (Eds.), Handbook of neuropsychology (pp. 91-106). Amsterdam: Elsevier.

Staresina, B. P., Fell, J., Do Lam, A. T., Axmacher, N., \& Henson, R. N. (2012). Memory signals are temporally dissociated in and across human hippocampus and perirhinal cortex. Nature Neuroscience, 15(8), 1167. https://doi.org/10.1038/nn.3154

Staresina, B. P., Fell, J., Dunn, J. C., Axmacher, N., \& Henson, R. N. (2013). Using state-trace analysis to dissociate the functions of the human hippocampus and perirhinal cortex in recognition memory. Proceedings of the National Academy of Sciences, 110(8), 3119-3124. https://doi.org/10.1073/pnas.1215710110 
Stark, S. M., Reagh, Z. M., Yassa, M. A., \& Stark, C. E. (2018). What's in a context? Cautions, limitations, and potential paths forward. Neuroscience Letters, 680, 77-87. https://doi.org/10.1016/i.neulet.2017.05.022

Squire, L. R. (2009). The legacy of patient HM for neuroscience. Neuron, 61(1), 6-9. https://doi.org/10.1016/j.neuron.2008.12.023

Suzuki, W. L., \& Amaral, D. G. (1994). Perirhinal and parahippocampal cortices of the macaque monkey: cortical afferents. Journal of Comparative Neurology, 350(4), 497-533. https://doi.org/10.1002/cne.903500402

Teuber, H. L. (1955). Physiological psychology. Annual Review of Psychology, 6(1), 267-296. https://doi.org/10.1146/annurev.ps.06.020155.001411

Tulving, E. (1985). Memory and consciousness. Canadian Psychology/Psychologie canadienne, 26(1), 1. http://dx.doi.org/10.1037/h0080017

Tulving, E. (2002). Episodic memory: From mind to brain. Annual Review of Psychology, 53(1), 125. https://doi.org/10.1146/annurev.psych.53.100901.135114

Turriziani, P., Oliveri, M., Salerno, S., Costanzo, F., Koch, G., Caltagirone, C., \& Carlesimo, G. A. (2008). Recognition memory and prefrontal cortex: dissociating recollection and familiarity processes using rTMS. Behavioural Neurology, 19(1-2), 23-27.

http://dx.doi.org/10.1155/2008/568057

Vaidya, A. R., Pujara, M. S., Petrides, M., Murray, E. A., \& Fellows, L. K. (2019). Lesion studies in contemporary neuroscience. Trends in Cognitive Sciences.

https://doi.org/10.1016/i.tics.2019.05.009

Vargha-Khadem, F., Gadian, D. G., Watkins, K. E., Connelly, A., Van Paesschen, W., \& Mishkin, M. (1997). Differential effects of early hippocampal pathology on episodic and semantic memory. Science, 277(5324), 376-380. https://doi.org/10.1126/science.277.5324.376

Verfaellie, M., \& Keane, M. M. (2017). Neuropsychological investigations of human amnesia: Insights into the role of the medial temporal lobes in cognition. Journal of the International Neuropsychological Society, 23(9-10), 732-740.

https://doi.org/10.1017/S1355617717000649

Vignal, J., Maillard, L., McGonigal, A., \& Chauvel, P. (2007). The dreamy state: Hallucinations of autobiographical memory evoked by temporal lobe stimulations and seizure. Brain, 130(1), 88-99. https://doi.org/10.1093/brain/awl329

Voss, J. L., Hauner, K. K., \& Paller, K. A. (2009). Establishing a relationship between activity reduction in human perirhinal cortex and priming. Hippocampus, 19(9), 773-778. https://doi.org/10.1002/hipo.20608 
Wais, P. E., Wixted, J. T., Hopkins, R. O., \& Squire, L. R. (2006). The hippocampus supports both the recollection and the familiarity components of recognition memory. Neuron, 49(3), 459-466. https://doi.org/10.1016/i.neuron.2005.12.020

Wang, W. C., Lazzara, M. M., Ranganath, C., Knight, R. T., \& Yonelinas, A. P. (2010). The medial temporal lobe supports conceptual implicit memory. Neuron, 68(5), 835-842. https://doi.org/10.1016/j.neuron.2010.11.009

Wang, W. C., Ranganath, C., \& Yonelinas, A. P. (2014). Activity reductions in perirhinal cortex predict conceptual priming and familiarity-based recognition. Neuropsychologia, 52, 19-26. https://doi.org/10.1016/i.neuropsychologia.2013.10.006

Whittlesea, B. W., \& Williams, L. D. (1998). Why do strangers feel familiar, but friends don't? A discrepancy-attribution account of feelings of familiarity. Acta Psychologica, 98(2-3), 141165. https://doi.org/10.1016/S0001-6918(97)00040-1

Wixted, J. T., \& Squire, L. R. (2004). Recall and recognition are equally impaired in patients with selective hippocampal damage. Cognitive, Affective, \& Behavioral Neuroscience, 4(1), 5866. https://doi.org/10.3758/CABN.4.1.58

Wixted, J. T., \& Mickes, L. (2010). A continuous dual-process model of remember/know judgments. Psychological Review, 117(4), 1025. https://doi.org/10.1037/a0020874..

Wixted, J. T., \& Squire, L. R. (2011). The medial temporal lobe and the attributes of memory. Trends in Cognitive Sciences, 15(5), 210-217. https://doi.org/10.1016/i.tics.2011.03.005

Wright, P., Randall, B., Clarke, A., \& Tyler, L. K. (2015). The perirhinal cortex and conceptual processing: Effects of feature-based statistics following damage to the anterior temporal lobes. Neuropsychologia, 76, 192-207. https://doi.org/10.1016/i.neuropsychologia.2015.01.041

Yeung, L. K., Olsen, R. K., Hong, B., Mihajlovic, V., D'Angelo, M. C., Kacollja, A., Ryan, J.D., \& Barense, M. D. (2019). Object-in-place memory predicted by anterolateral entorhinal cortex and parahippocampal cortex volume in older adults. Journal of Cognitive Neuroscience, 31(5), 711-729. https://doi.org/10.1162/jocn_a_01385

Yonelinas, A. P., \& Jacoby, L. L. (1994). Dissociations of processes in recognition memory: effects of interference and of response speed. Canadian Journal of Experimental Psychology/Revue canadienne de psychologie expérimentale, 48(4), 516.

Yonelinas, A. P. (2002). The nature of recollection and familiarity: A review of 30 years of research. Journal of Memory and Language, 46(3), 441-517. https://doi.org/10.1006/jmla.2002.2864 
Yonelinas, A. P., Kroll, N. E., Quamme, J. R., Lazzara, M. M., Sauvé, M. J., Widaman, K. F., \& Knight, R. T. (2002). Effects of extensive temporal lobe damage or mild hypoxia on recollection and familiarity. Nature Neuroscience, 5(11), 1236.

https://doi.org/10.1038/nn961

Yonelinas, A. P., Quamme, J. R., Widaman, K. F., Kroll, N. E. A., Sauve, M. J., \& Knight, R. T. (2004). Mild hypoxia disrupts recollection, not familiarity. Cognitive, Affective, \& Behavioral Neuroscience, 4(3), 393-400. https://doi.org/10.3758/CABN.4.3.393 